\title{
The effect of weekend versus weekday admission on outcomes of esophageal variceal hemorrhage
}

\author{
Robert P Myers MD MSc, Gilaad G Kaplan MD MPH, Abdel Aziz M Shaheen MD MPH
}

\begin{abstract}
RP Myers, GG Kaplan, AAM Shaheen. The effect of weekend versus weekday admission on outcomes of esophageal variceal hemorrhage. Can J Gastroenterol 2009;23(7):495-501.
\end{abstract}

BACKGROUND: Hospital staffing is often lower on weekends than weekdays, and may contribute to higher mortality in patients admitted on weekends. Because esophageal variceal hemorrhage $(E V H)$ requires complex management and urgent endoscopic intervention, limitations in physician expertise and the availability of endoscopy on weekends may be associated with increased EVH mortality.

OBJECTIVE: To assess the differences in mortality, hospital length of stay (LOS), and costs between patients admitted on weekends versus patients who were admitted on weekdays.

METHODS: The United States Nationwide Inpatient Sample database was used to identify patients hospitalized for EVH between 1998 and 2005. Differences in mortality, LOS, and costs between patients admitted on weekends and weekdays were evaluated using regression models with adjustment for patient and clinical factors, including the timing of endoscopy.

RESULTS: Between 1998 and 2005, 36,734 EVH admissions to 2207 hospitals met the inclusion criteria. Compared with patients admitted on weekdays, individuals admitted on the weekend were slightly less likely to undergo endoscopy on the day of admission (45\% versus $43 \%$, respectively; $\mathrm{P}=0.01)$ and by the second day ( $81 \%$ versus $75 \% ; \mathrm{P}<0.0001)$. However, mortality $(11.3 \%$ versus $10.8 \% ; \mathrm{P}=0.20)$ and the requirement for endoscopic therapy (70\% versus $69 \%$; $\mathrm{P}=0.08$ ) or portosystemic shunt insertion $(4.4 \%$ versus $4.7 \% ; \mathrm{P}=0.32)$ did not differ between weekend and weekday admissions. After adjusting for confounding factors, including the timing of endoscopy, the risk of mortality was similar between weekend and weekday admissions (OR 1.05; 95\% CI 0.97 to 1.14 ). Although LOS was similar between groups, adjusted hospital charges were $4.0 \%$ greater (95\% CI 2.3 to $5.8 \%$ ) for patients hospitalized on the weekend.

CONCLUSIONS: In patients with EVH, admission on the weekend is associated with a small delay in receiving endoscopic intervention, but no difference in mortality or the requirement for portosystemic shunt insertion. The weekend effect observed for some medical and surgical conditions does not apply to patients with EVH.

Key Words: Cirrhosis; Database; Health services research; Hemorrhage; Outcome assessment; Portal hypertension

\author{
Effet d'une admission la fin de semaine plutôt \\ qu'un jour de semaine sur l'issue de l'hémorragie \\ par rupture de varices asophagiennes
}

CONTEXTE : Il y a souvent moins de personnel dans les hôpitaux les
jours de fin de semaine que de semaine et cela peut contribuer à une
mortalité plus élevée chez les patients admis la fin de semaine. Étant donné
que l'hémorragie par rupture des varices œesophagiennes (HVO) requiert
un traitement complexe et une intervention endoscopique urgente, l'accès
limité à l'expertise médicale et à l'endoscopie les fins de semaine pourrait
être associé à une mortalité par HVO accrue.
OBJECTIFS : Évaluer les différences de mortalité, de durée des séjours
hospitaliers (DSH) et de coûts selon que les patients sont admis la fin de
semaine ou un jour de semaine.
MÉTHODES : La base de données Nationwide Inpatient Sample des
États-Unis a permis recenser les patients hospitalisés pour HVO entre 1998
et 2005. Les différences de mortalité, de DSH et de coûts, selon que les
patients étaient admis la fin de semaine ou un jour de semaine ont été
évaluées à l'aide de modèles de régression, avec ajustements pour tenir
compte de facteurs liés aux patients et de facteurs cliniques, dont le
moment de l'endoscopie. RÉSULTATS : Entre 1998 et 2005, 36734 admissions pour HVO dans 2207 hôpitaux répondaient aux critères d'admissibilité. Comparativement aux patients admis un jour de semaine, les sujets admis la fin de semaine étaient un peu moins susceptibles de subir une endoscopie le jour même de leur admission ( $45 \%$ vs $43 \%$, respectivement, p = 0,01) et le lendemain ( $81 \%$ vs $75 \%, \mathrm{p}<0,0001)$. Toutefois, la mortalité ( $11,3 \%$ vs $10,8 \%, \mathrm{p}=0,20)$ et la nécessité d'un traitement endoscopique ( $70 \%$ vs $69 \%, \mathrm{p}=0,08$ ) ou d'une pose de shunt portosystémique $(4,4 \%$ vs $4,7 \%, \mathrm{p}=0,32)$ n'ont pas été différentes, selon que les admissions se faisaient un jour de semaine ou de fin de semaine. Après ajustement pour tenir compte des facteurs de confusion, dont le moment de l'endoscopie, le risque de mortalité s'est révélé similaire selon que les admissions avaient eu lieu un jour de semaine ou de fin de semaine (RC 1,05, IC à $95 \%, 0,97$ à 1,14). Bien que la DSH ait été similaire entre les groupes, les frais hospitaliers ajustés ont été de 4,0\% supérieurs (IC à $95 \%, 2,3$ à 5,8\%) pour les patients hospitalisés une fin de semaine.

CONCLUSIONS : Chez les patients présentant une HVO, l'admission une fin de semaine est associée à un léger retard de l'intervention endoscopique, mais elle n'est associée à aucune différence sur le plan de la mortalité ou de la nécessité de poser un shunt portosystémique. L'effet « fin de semaine » typique observé avec certains problèmes de santé qui relèvent de la médecine ou de la chirurgie ne semble pas s'appliquer aux patients souffrant d'HVO.

ruptured abdominal aortic aneurysm), the treatment of which is considered particularly sensitive to variations in the levels of hospital staffing. The study also demonstrated increased mortality among patients hospitalized on the weekend for 23 of the 100 most frequent causes of death. None of the diseases showed the opposite pattern (1). The literature describing the weekend effect in hepatobiliary disorders is sparse. In one study (1), patients hospitalized for chronic liver disease and cirrhosis had similar mortality regardless of the day of admission. On the demonstrated an association between weekend hospital admission and increased mortality. The 'weekend effect' has been attributed to reduced hospital staffing and/or access to specific intensive treatments and procedures performed on the weekend (1-7). In a recent study, Bell and Redelmeier (1) described an increase of at least $15 \%$ in relative mortality for Canadian patients hospitalized on the weekend with one of three conditions (acute epiglottitis, pulmonary embolism or

Liver Unit, Division of Gastroenterology, Department of Medicine, University of Calgary, Calgary, Alberta

Correspondence: Dr Robert P Myers, Liver Unit, University of Calgary, 6D22, Teaching, Research and Wellness Building,

3280 Hospital Drive Northwest, Calgary, Alberta T2N 4N1. Telephone 403-592-5049, fax 403-592-5090, e-mail rpmyers@ucalgary.ca

Received for publication November 26, 2008. Accepted January 7, 2009 
contrary, an increased risk of death was reported in patients hospitalized on the weekend for cholangiocarcinoma and hepatocellular carcinoma (HCC). With respect to upper gastrointestinal bleeding (UGIB), some, but not all, studies have demonstrated a weekend effect $(1,2,8)$. For example, we recently described a $13 \%$ relative increase in the risk of death among patients admitted on the weekend for peptic ulcer-related UGIB (9).

Hemorrhage from esophageal varices is a common complication of cirrhosis, with a high short-term mortality rate. Optimizing the outcomes of patients with variceal bleeding requires early initiation of aggressive resuscitative efforts, specific treatment aimed at arresting the bleeding episode (eg, pharmacological and endoscopic therapies) as well as supportive care of the complications of cirrhosis (eg, ascites, encephalopathy and hepatorenal syndrome) (10,11). Because many endoscopy units are not routinely staffed on weekends, delays in performing upper endoscopy may have the potential to contribute to poorer outcomes in patients hospitalized on Saturdays and Sundays. Thus, esophageal variceal hemorrhage (EVH) represents an ideal condition in which to study the weekendweekday mortality relationship.

Thus far, no study has examined the weekend effect in patients with bleeding esophageal varices. Therefore, the objectives of our study were to compare mortality rates between patients admitted with EVH on weekends versus those admitted on weekdays, and to determine whether any differences in mortality could be explained by differential timing of upper endoscopy.

\section{METHODS}

\section{Data source}

Data were extracted from the Healthcare Cost and Utilization Project Nationwide Inpatient Sample (NIS) database for the years 1998 to 2005 (12). The NIS is the largest all-payer database of national hospital discharges (approximately eight million per annum) maintained by the Agency for Healthcare Research and Quality (Maryland, USA). It represents a 20\% stratified random sample of nonfederal acute care hospitals in the United States, including community, general and academic centres, but not long-term care facilities. Stratified random sampling ensures that the database is representative of the United States population and that it accounts for approximately $90 \%$ of all hospitalizations. Each data entry includes a patient identifier, demographic data, hospital transfer status, admission type (emergency, urgent or elective), primary and secondary diagnoses (as many as 15), procedures (as many as 15), insurance status, hospital charges, length of stay (LOS) and hospital characteristics. Because each record is for a single hospitalization, not a person, there could be multiple records for an individual if they had several hospitalizations. The NIS data compared favourably with the National Hospital Discharge Survey, supporting the validity of this database (13). Quality control and validation of the NIS are performed by the Agency for Healthcare Research and Quality (12).

\section{Study sample}

The methods for identifying the study cohort were decribed previously (14). Briefly, the International Classification of Diseases 9th Revision, Clinical Modification (ICD-9-CM) diagnosis codes $(456.0,456.20)$ were used to identify adult patients (18 years of age and older) who were nonelectively hospitalized with a primary diagnosis of EVH between 1998 and $2005(n=48,735)(15)$. Hospital admissions with a secondary diagnosis of variceal bleeding if the primary diagnosis was a liver-related condition (the specific conditions and their corresponding ICD-9-CM codes are presented in the Appendix were included. Patients who did not undergo upper endoscopy $(n=6751)$ were excluded because this procedure is necessary to eliminate nonvariceal causes of UGIB. Patients who underwent transplantion during their hospitalization $(n=174)$ were also excluded because they were likely to have very different outcomes from the majority of patients, and those with missing data regarding in-hospital mortality (predominantly transfers to other institutions $[n=6373]$ ) were excluded because this was our primary outcome measure. Finally, because the primary variable of interest was weekend versus weekday admission, patients with missing data regarding the day of admission were excluded $(\mathrm{n}=94)$.

\section{Study variables}

The primary outcome measure was in-hospital mortality. The use of upper endoscopy and portosystemic shunt procedures, LOS and hospital charges were also assessed. Charges were adjusted for inflation to 2005 US dollars using the United States Consumer Price Index for medical care (16).

The primary exposure variable was admission on weekends (Saturday or Sunday) versus weekdays. The NIS database does not allow identification of specific admission days (eg, Friday versus Saturday) or admission hours. Covariates included age, sex, race (Caucasian versus non-Caucasian), type of health insurance (private versus nonprivate), etiology of liver disease (alcoholic cirrhosis versus other), admission status, hospital characteristics (geographical location and teaching status) and the year of admission. Case-mix adjustment was performed using the Elixhauser list of 30 comorbidities (17), a well validated algorithm for predicting in-hospital mortality, LOS and hospital charges due to a variety of conditions including cirrhosis (18). Because the algorithm includes liver disease and coagulopathy as comorbidities, these variables were excluded, leaving 28 comorbid conditions for summation (categorized as $0,1,2$, and 3 or more). Because liver disease severity is an important predictor of mortality due to variceal bleeding (19-23), and laboratory data are not available in the NIS for calculation of the Child-Pugh or Model for End-Stage Liver Disease scores (24), features of hepatic decompensation using ICD-9-CM diagnosis codes, as previously described (14), were controlled for. Specifically, the presence of ascites (ICD-9-CM code 789.5), hepatic encephalopathy (ICD-9-CM 572.2), hepatorenal syndrome (ICD-9-CM 572.4), spontaneous bacterial peritonitis (ICD-9-CM 567.2) and coagulopathy (as defined by Elixhauser et al [17]) were identified. Because of the frequent coexistence of these complications, they were combined into a single dichotomous variable (none versus one or more complication) to avoid introducing multicollinearity in our multivariate models (see below). The presence of HCC (ICD-9-CM code 155.0), which is associated with increased mortality due to esophageal variceal bleeding, was also identifed $(14,19,25)$. Finally, as surrogates for the severity of the bleeding episode, receipt of a blood transfusion (ICD-9-CM code 99.04), balloon tamponade (ICD-9-CM 44.93, 96.06) and portosystemic shunt (ICD-9-CM 39.1) were identified (14). 


\section{Statistical analysis}

Patient characteristics and the timing of upper endoscopy and portosystemic shunt insertion among patients admitted on weekends versus weekdays were compared using $\chi^{2}, t$ tests and logistic regression. To examine the independent association between in-hospital mortality and weekend versus weekday admission, multiple logistic regression models were used to account for the potential confounding effects of patient demographics, admission status, comorbidities, procedures, hospital characteristics and year of admission. Multiple linear regression analyses were also used to adjust for confounders in comparing LOS and hospital charges between weekend and weekday admissions. LOS and charges were logarithmically transformed due to their skewed distributions.

A potential source of bias in the present study is that scheduled admissions would be more likely to occur on weekdays and that such patients would likely have better outcomes than those admitted on weekends when scheduled admissions are unlikely (2). For example, a patient with a small UGIB may present to their regular physician on a weekday and be admitted directly to hospital rather than via an emergency department (ED). To examine the effect of this potential source of bias, sensitivity analyses were conducted in three restricted cohorts:

1. Emergently admitted patients (urgent admissions excluded);

2. Patients admitted through EDs (transfers from other institutions excluded); and

3. Patients admitted emergently from an ED.

In addition, whether any difference in mortality between weekend and weekday admissions could be explained by differences in the timing of upper endoscopy was investigated. For these analyses, patients with missing data regarding the day of endoscopy, or procedural wait times longer than seven days because of the possibility of an in-hospital complication or diagnosis different from that prompting admission $(n=6366$ patients excluded; $17 \%$ of both groups) were excluded. Delayed endoscopy would be considered to mediate the association between weekend admission and mortality if the OR was attenuated when this variable was added to the models.

All models used generalized estimating equations to account for the hierarchical nature of the data (ie, clustering of discharges within hospitals) (26). Statistical analyses were performed using SAS-callable SUDAAN (version 9.0.1, Research Triangle Institute, USA) to account for the complex sampling design of the NIS (12). Discharge-level weights published by the Health Care Utilization Project were used to produce 95\% CIs for point estimates and to reflect nationwide data during the study period (27).

\section{Patient characteristics}

\section{RESULTS}

Between 1998 and 2005, there were 36,734 admissions to 2207 hospitals for esophageal variceal bleeding that met the inclusion criteria. There were several small, but statistically significant differences in baseline characteristics between patients admitted on weekdays versus weekends (Table 1 ). The only clinically significant difference was a higher frequency of emergent admissions for patients hospitalized on the weekend versus patients hospitalized on a weekday $(68.2 \%$ versus $64.2 \%$, respectively; $\mathrm{P}<0.0001)$. The number of comorbid conditions,
TABLE 1

Characteristics of weekday and weekend admissions for esophageal variceal bleeding

\begin{tabular}{|c|c|c|c|}
\hline \multirow[b]{2}{*}{ Characteristic } & \multicolumn{2}{|c|}{ Admissions } & \multirow[b]{2}{*}{$\mathbf{P}$} \\
\hline & $\begin{array}{l}\text { Weekday } \\
(n=27,497)\end{array}$ & $\begin{array}{l}\text { Weekend } \\
(n=9237)\end{array}$ & \\
\hline \multicolumn{4}{|l|}{ Demographics } \\
\hline $\begin{array}{l}\text { Age, years (median } \\
\text { [Interquartile range]) }\end{array}$ & $\begin{array}{c}51.9 \\
(44.8-61.8)\end{array}$ & $\begin{array}{c}51.8 \\
(44.8-61.6)\end{array}$ & 0.29 \\
\hline Women & 29.5 & 29.4 & 0.87 \\
\hline Caucasian & 49.8 & 49.5 & 0.60 \\
\hline Private health insurance & 31.7 & 30.6 & 0.05 \\
\hline \multicolumn{4}{|l|}{ Hospital characteristics } \\
\hline Rural & 8.6 & 8.8 & 0.13 \\
\hline Urban, nonteaching & 43.8 & 44.8 & \\
\hline Urban, teaching & 47.6 & 46.4 & \\
\hline \multicolumn{4}{|c|}{ Hospital geographical location (United States) } \\
\hline Northeast & 17.0 & 16.1 & 0.32 \\
\hline South & 16.2 & 16.1 & \\
\hline Midwest & 38.7 & 39.3 & \\
\hline West & 28.2 & 28.5 & \\
\hline \multicolumn{4}{|l|}{ Admission details } \\
\hline Transferred in & 4.5 & 4.2 & 0.22 \\
\hline Emergency & 64.2 & 68.2 & $<0.0001$ \\
\hline \multicolumn{4}{|l|}{ Comorbid conditions, $\mathrm{n}$} \\
\hline 0 & 11.1 & 10.0 & 0.04 \\
\hline 1 & 29.0 & 29.5 & \\
\hline 2 & 30.4 & 30.6 & \\
\hline$\geq 3$ & 29.6 & 29.9 & \\
\hline \multicolumn{4}{|l|}{ Liver-related variables } \\
\hline Alcoholic cirrhosis & 50.9 & 52.0 & 0.06 \\
\hline Hepatic decompensation & 54.6 & 55.8 & 0.07 \\
\hline Hepatic encephalopathy & 14.2 & 13.9 & 0.44 \\
\hline Ascites & 28.3 & 28.2 & 0.91 \\
\hline Hepatorenal syndrome & 1.8 & 1.7 & 0.69 \\
\hline $\begin{array}{l}\text { Spontaneous bacterial } \\
\text { peritonitis }\end{array}$ & 1.4 & 1.3 & 0.86 \\
\hline Coagulopathy & 31.7 & 33.8 & 0.0001 \\
\hline $\begin{array}{l}\text { Hepatocellular } \\
\text { carcinoma }\end{array}$ & 2.6 & 2.4 & 0.24 \\
\hline
\end{tabular}

Data are presented as proportions (\%) unless otherwise specified. Comparisons between groups were made using a t test for age and $\chi^{2}$ tests for categorical variables

etiology of cirrhosis, prevalence of HCC and manifestations of hepatic decompensation were similar between the two groups.

Upper endoscopy and other procedures

The proportions of patients requiring endoscopic therapy (band ligation and/or sclerotherapy) (70\% versus $69 \% ; \mathrm{P}=0.08)$, balloon tamponade $(0.06 \%$ versus $0.06 \% ; \mathrm{P}=0.73)$ and blood transfusion ( $44 \%$ versus $45 \%$; $\mathrm{P}=0.35$ ) were not significantly different between weekday and weekend admissions. The mean ( \pm SE) time to endoscopy was similar between groups (weekend $1.14 \pm 0.03$ days versus weekday $1.12 \pm 0.03$ days; $\mathrm{P}=0.60$ ); however, patients admitted on the weekend were less likely to undergo endoscopy on the day of admission (43\% versus 45\%; $\mathrm{P}=0.01$; Table 2). This difference was most pronounced by the 
TABLE 2

Timing of upper endoscopy and portosystemic shunt insertion according to weekday versus weekend admission

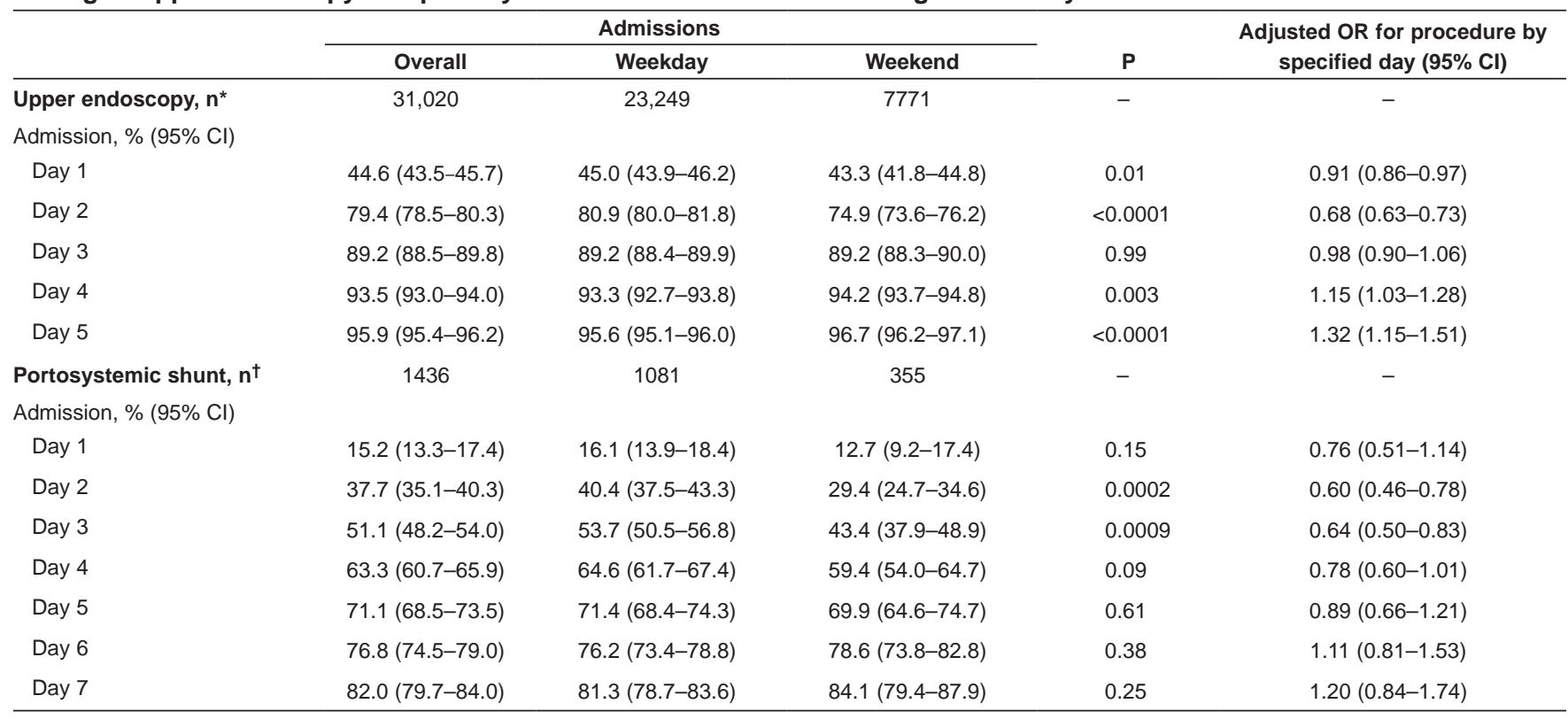

Models were adjusted for age, sex, race, heath insurance, liver-related variables, comorbidities, hospital and admission characteristics, year and procedures. Patients admitted on a weekday formed the reference group in all analyses. *Analyses were limited to patients with data regarding the timing of upper endoscopy. Percentages reflect cumulative proportion of patients who had endoscopy or received a shunt by the specified day. ${ }^{\dagger}$ Analyses were limited to patients who received a portosystemic shunt and in whom data regarding the timing of shunt insertion were available

second day, at which time $81 \%$ of patients admitted on a weekday had undergone endoscopy versus $75 \%$ of those admitted on the weekend (adjusted OR 0.68; 95\% CI 0.63 to 0.73 ; $\mathrm{P}<0.0001)$. After the second day, there were several small but statistically significant differences in the timing of endoscopy between patients admitted on the weekend versus those admitted on a weekday.

The proportion of patients requiring portosystemic shunt insertion was similar between weekend and weekday admissions (4.4\% versus $4.7 \%$; OR $0.94 ; 95 \%$ CI 0.84 to 1.06 ; $\mathrm{P}=0.32$ ). In an analysis restricted to patients in whom data regarding the timing of shunt insertion was available $(n=1436$; $83 \%$ to $88 \%$ of both groups who received a shunt), the mean time to insertion was longer for weekend admissions $(4.12 \pm 0.25$ days versus $3.69 \pm 0.13$ days), although this difference did not reach statistical significance $(P=0.13)$. However, patients admitted on the weekend were less likely to receive their shunt during each of the first three days of their hospitalization, a difference that persisted after adjustment for patient and hospital characteristics (Table 2). For example, only $43 \%$ of patients admitted on the weekend who received a shunt did so by day 3 versus $54 \%$ of those admitted on a weekday (adjusted OR 0.64; 95\% CI 0.50 to 0.83 ).

\section{In-hospital mortality}

Overall, $10.9 \%$ (95\% CI $10.5 \%$ to $11.3 \%$ ) of patients died. In-hospital mortality was not significantly different between patients admitted on the weekend $(11.3 \%$; $95 \% \mathrm{CI} 10.6 \%$ to $12.0 \%)$ versus those admitted on a weekday $(10.8 \% ; 95 \% \mathrm{CI}$ $10.3 \%$ to $11.3 \%$; unadjusted OR $1.05 ; 95 \%$ CI 0.97 to 1.14 ; $\mathrm{P}=0.20)$. Significant independent predictors of mortality included male sex, older age, nonprivate health insurance, alcoholic cirrhosis, HCC, features of hepatic decompensation and an increased number of comorbid conditions (Figure 1). Mortality was also higher for transfers from other institutions, and patients admitted emergently or to hospitals in the northeastern United States or during the earlier years of the study interval (2005 versus 1998: OR 0.75; 95\% CI 0.64 to 0.88). Finally, patients who received a blood transfusion, balloon tamponade or portosystemic shunt were at greater risk of death. Endoscopic therapy such as band ligation or sclerotherapy was not a significant predictor of mortality (Figure 1). After adjustment for these characteristics, the OR for death among patients admitted on a weekend, compared with those admitted on a weekday, was 1.05 (95\% CI 0.97 to 1.14 ). The number of days to endoscopy (OR per additional day $0.94 ; 95 \%$ CI 0.90 to 0.98 ) and having undergone endoscopy on the day of admission (OR 1.45; 95\% CI 1.33 to 1.59 ) were significant predictors of mortality. In separate models including these variables, the odds of mortality in patients admitted on the weekend versus weekdays was similar to that observed in the primary analysis (OR 1.08; 95\% CI 0.98 to 1.18 , in both models).

\section{Sensitivity analyses}

Restricting our cohort to patients admitted emergently and/or from an ED did not affect the nonsignificant association between weekend admission and mortality observed in the primary analysis. Specifically, the ORs for mortality comparing weekend with weekday admissions in analyses restricted to patients admitted via an ED $(n=29,982)$, emergently versus urgently $(n=23,869)$ and patients admitted emergently via an ED $(n=21,465)$ were 1.03 (95\% CI 0.94 to 1.12$), 1.02$ (95\% CI 0.92 to 1.13 ) and 1.00 (95\% CI 0.91 to 1.11$)$, respectively.

\section{LOS and hospital charges}

Overall, the median LOS was 3.9 days (interquartile range [IQR] 2.4 days to 6.4 days) and median total charge was 


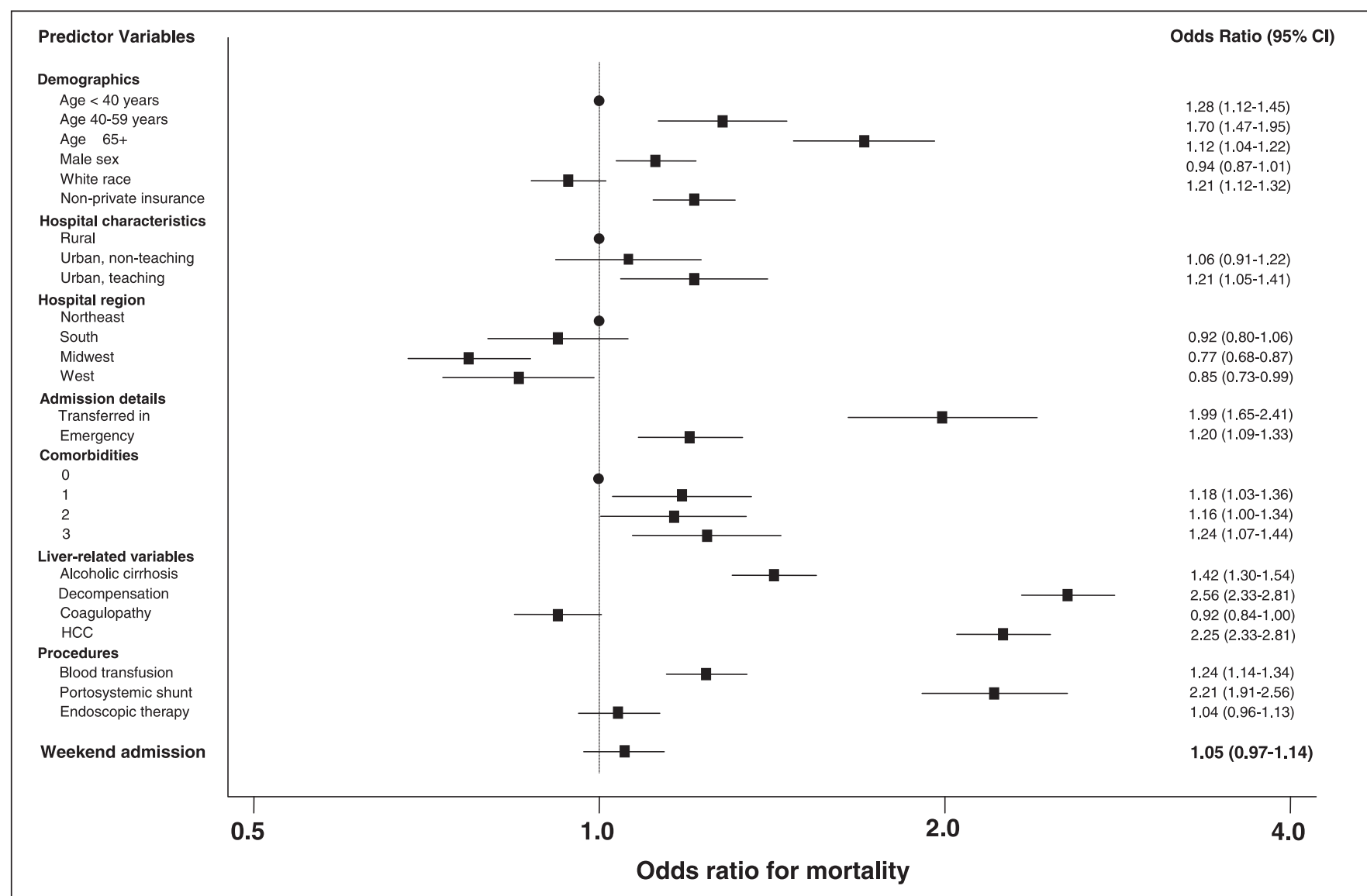

Figure 1) Predictors of in-hospital mortality in patients hospitalized for esophageal variceal hemorrhage. Weekend admission was not associated with an increased risk of mortality over weekday admission (OR 1.05; 95\% CI 0.97 to 1.14). Note: the x-axis is on a logarithmic scale and reference groups for polychotomous variables are illustrated by circles. For ease of presentation, the ORs (95\% CI) for balloon tamponade (OR 18.7; 13.2 to 26.5) and year of admission (2005 versus 1998: OR 0.75; 0.64 to 0.88) are not illustrated. HCC Hepatocellular carcinoma

$\$ 21,147$ per patient (range $\$ 13,247$ to $\$ 36,534$ ). Although adjusted LOSs did not differ significantly between patients admitted on the weekend versus weekdays ( $\mathrm{P}=0.051)$, patients admitted on the weekend had a $4.0 \%$ (95\% CI 2.3\% to $5.8 \%$ ) increase in adjusted hospital charges (median [IQR] weekend, $\$ 21,911[\$ 13,885$ to $\$ 36,808]$ versus weekdays $\$ 20,925[\$ 13,035$ to $\$ 36,425])$.

\section{DISCUSSION}

In-hospital mortality did not differ between patients hospitalized on the weekend versus weekdays for esophageal variceal bleeding. To our knowledge, our study is the first to examine the weekend effect in patients with variceal hemorrhage. Our findings are consistent with several studies that described mortality according to the day of admission for unspecified UGIB. For example, Bell and Redelmeier (1) reported no difference in mortality in a cohort of 30,129 Canadian patients (OR 1.08; 95\% CI 0.96 to 1.20 ), and Schmulewitz et al (8) failed to detect a significant weekend effect among 584 Scottish patients hospitalized for UGIB (OR 1.65; 95\% CI 0.69 to 3.71). Similarly, in a study of emergency UGIB admissions in California (USA), Cram et al (2) reported similar mortality among patients hospitalized on the weekend versus weekdays (OR 1.14; 95\% CI 0.92 to 1.42). Importantly, none of these studies controlled for potential confounding by disease-specific markers of illness severity that may differ between patients hospitalized on the weekend and those on weekdays. Our adjustment for the magnitude of bleeding - based on receipt of blood transfusions, endoscopic therapy, balloon tamponade or portosystemic shunt insertion - and severity of the underlying liver disease, as reflected by features of hepatic decompensation, represents a major strength of our analysis. Moreover, because the NIS is a population-based, nationwide database, our results are representative of outcomes and practices across the United States rather than in single states, provinces or even hospitals described in the aforementioned publications $(1,2,8)$.

There are several potential explanations for our findings. First, a weekend effect may simply not exist for this condition. In Bell and Redelmeier's study (1), a significant increase in mortality among patients admitted on the weekend was observed for only 23 of 100 conditions. Likewise, Cram et al (2) reported a weekend effect for only three of 50 disorders (duodenal ulcer, cancer of the ovary/uterus and cardiovascular symptoms). Thus, hospitalization on the weekend is associated with similar outcomes for the majority of medical and surgical conditions. Most studies (1-7) have hypothesized that the weekend effect is attributable to reduced hospital staffing and/or 
access to specific intensive treatments and procedures on the weekend. In this regard, it is not overly surprising that we did not observe a similar effect in patients with variceal hemorrhage. Current consensus guidelines $(10,11)$ recommend that most patients with evidence of liver disease who present with substantial UGIB are assumed to have variceal hemorrhage until proven otherwise. Accordingly, these patients usually receive vasopressor therapy (eg, somatostatin analogues or terlipressin) and expedited upper endoscopy regardless of the day of the week. Conversely, patients without evidence of liver disease and, perhaps, less significant UGIB are more likely to have their endoscopy delayed. Results from the current study and a similar analysis of NIS data in patients with peptic ulcerrelated hemorrhage (9) support these assumptions. Specifically, $45 \%$ of patients with variceal bleeding underwent endoscopy on the day of admission versus only $33 \%$ of those with peptic ulcer disease (9). An alternative explanation for our findings is that our assessment of the influence of weekend admission on mortality is an underestimate because patients admitted on weekends typically 'crossover' to receive weekday care and vice versa (2). Finally, we cannot exclude unmeasured differences between processes of care and patient characteristics between weekend and weekday admissions that may have confounded our results. For example, due to limitations in the NIS database, we could not address issues that are vital to the outcomes of variceal bleeding including the quality of resuscitation, endoscopic therapy and general medical care of the cirrhotic patient, or the use of antibiotics for prophylaxis of bacterial infections $(10,11)$. Similarly, limitations in clinical and laboratory data in the NIS database hinder complete adjustment for the severity of the bleeding episode or underlying liver disease (eg, using the Child-Pugh or Model for End-Stage Liver Disease scores) (24). We would argue, however, that patients admitted on the weekend were slightly sicker than individuals hospitalized during the week. For example, weekend patients had a higher prevalence of coagulopathy and were more likely to be admitted emergently (Table 1 ). Such incomplete casemix adjustment would tend to exaggerate any mortality increase observed in weekend patients and the increase that we observed was not statistically significant.

Although overall in-hospital mortality due to variceal hemorrhage was similar between weekday and weekend admissions, weekend patients were less likely to undergo endoscopy within the first few days of admission, although differences were small. For example, by the end of the second day, $81 \%$ of patients hospitalized on a weekday had undergone endoscopy versus $75 \%$ of those admitted on the weekend (OR 0.68; 95\% CI 0.63 to 0.73 ). Similarly, the proportion of patients who received a portosystemic shunt within the first few days of admission was significantly lower among weekend hospitalizations ( $43 \%$ versus $54 \%$ admitted on a weekday; OR $0.64 ; 95 \%$ CI 0.50 to 0.83 ). These findings support previous studies demonstrating the impact of weekend admissions on the timeliness of certain procedures and tests. For example, in an analysis of 126,754 patients admitted emergently in Canada, Bell and Redelmeier (28) described longer mean wait times for upper endoscopy (2.1 days versus 1.9 days), echocardiography (2.5 days versus 2.3 days), and ventilation-perfusion lung scanning (1.9 days versus 1.4 days; $\mathrm{P}<0.0001$ for all comparisons) among patients hospitalized on the weekend. Similarly, Kostis et al (4) reported significant reductions in rates of cardiac catheterization, coronary angioplasty and coronary artery bypass grafting by the second day of admission in an analysis of New Jersey (USA) hospitalizations for acute myocardial infarction. The magnitudes of these reductions were similar to those observed in our analysis, and several of these differences persisted 30 days after admission. The authors concluded that these delays mediated, at least in part, the $7.5 \%$ relative increase in 30 -day mortality observed among patients hospitalized on the weekend. Our results suggest that delays in endoscopic intervention in weekend patients are not long enough to increase the in-hospital death rate in this subgroup. In fact, our multivariate analysis suggests that the timing of endoscopy is likely a reflection of the severity of patient presentation rather than a mediator of mortality. Specifically, for each additional day of delay to endoscopy, the odds of mortality decreased 6\%. Similarly, endoscopy on the day of admission was associated with a $45 \%$ increase in the odds of death. These findings suggest that American clinicians are appropriately triaging their patients such that especially sick individuals receive accelerated endoscopy whereas endoscopy is delayed in those who are less severely ill. An alternative, but far less likely explanation, is that early endoscopy is harmful, for example, due to an increased risk of complications such as oxygen desaturation (29).

In addition to mortality, we describe a $4 \%$ increase in adjusted hospital charges in patients hospitalized for variceal bleeding on the weekend. LOS did not differ between groups. Similar findings have been reported for other conditions $(9,30)$. For example, in a study of percutaneous coronary revascularization, Ellis et al (30) identified weekend delays as a factor associated with higher costs. In patients with peptic ulcer-related hemorrhage, weekend admission is associated with a 6\% increase in hospital charges (9). These effects may be mediated, at least in part, by delays in receiving endoscopy for patients admitted on the weekend. Alternatively, more intensive resource use by more severely ill patients hospitalized on the weekend (as described above) may have played a role. As expected, measures of increased disease severity and the use of certain procedures (eg, portosystemic shunts) were associated with higher costs in our analysis (data not shown).

Our study has several limitations. As with all studies using administrative data, the validity of the diagnosis and procedure codes we used must be considered (31). It is unlikely, however, that the accuracy of this information would systematically vary between weekend and weekday admissions. Secondly, a substantial number of patients were excluded from our analyses because of endoscopic details and missing data regarding mortality - predominantly transfers to other institutions. These patients may have differed in disease severity from those included in our cohort. For example, more severely ill patients may have been transferred to other institutions (eg, tertiary care centres) and thus excluded from our analyses. This issue highlights a limitation of the NIS database, namely that linkage of individual patients between or within hospitals cannot be performed; thus, we could not adjust for within-patient correlations (ie, in those with multiple admissions). Finally, our mortality analyses were limited to in-hospital deaths. Whether an association exists between weekend admission and increased mortality due to variceal bleeding over longerterm follow-up (eg, at 30 days or one year), as observed in some conditions $(4,5)$, warrants investigation. 


\section{SUMMARY}

The weekend effect observed for some conditions does not apply to patients hospitalized for EVH. Although patients admitted on the weekend are more likely to have delayed endoscopy and portosystemic shunt insertion, these differences do not contribute to an increased risk of mortality in these patients.

ACKNOWLEDGEMENTS: Dr Robert Myers is funded by a Clinical Investigator Award from the Alberta Heritage Foundation for Medical Research, and a New Investigator Award from the Canadian Institutes for Health Research.

\begin{tabular}{lc} 
APPENDIX & \\
International Classification of Diseases, 9th Revision- \\
Clinical Modification (ICD-9-CM) diagnosis codes used to \\
indicate the presence of liver-related conditions \\
\hline Liver-related condition & $\begin{array}{c}\text { ICD-9-CM } \\
\text { diagnosis code }\end{array}$ \\
\hline Acute and subacute necrosis & 570 \\
Chronic liver disease and cirrhosis & $571 . x$ \\
Liver abscess and sequelae of chronic liver disease & $572 . x$ \\
Other disorders of the liver & $573 . x$ \\
Viral hepatitis & $070 . x$ \\
Malignant neoplasm of liver, primary (hepatocellular & 155.0 \\
carcinoma) & \\
Malignant neoplasm of liver, intrahepatic bile ducts & 155.1 \\
(cholangiocarcinoma) & \\
Disorders of iron metabolism (hemochromatosis) & 275.0 \\
Disorders of copper metabolism (Wilson's disease) & 275.1 \\
Portal vein thrombosis & 452 \\
\hline
\end{tabular}

\section{REFERENCES}

1. Bell CM, Redelmeier DA. Mortality among patients admitted to hospitals on weekends as compared with weekdays. N Engl J Med 2001;345:663-8.

2. Cram P, Hillis SL, Barnett M, Rosenthal GE. Effects of weekend admission and hospital teaching status on in-hospital mortality. Am J Med 2004;117:151-7.

3. Barnett MJ, Kaboli PJ, Sirio CA, Rosenthal GE. Day of the week of intensive care admission and patient outcomes: A multisite regional evaluation. Med Care 2002;40:530-9.

4. Kostis WJ, Demissie K, Marcella SW, Shao YH, Wilson AC, Moreyra AE. Weekend versus weekday admission and mortality from myocardial infarction. N Engl J Med 2007;356:1099-109.

5. Becker DJ. Do hospitals provide lower quality care on weekends? Health Serv Res 2007;42:1589-612.

6. Saposnik G, Baibergenova A, Bayer N, Hachinski V. Weekends: A dangerous time for having a stroke? Stroke 2007;38:1211-5.

7. Mangold WD. Neonatal mortality by the day of the week in the 1974-75 Arkansas live birth cohort. Am J Public Health 1981;71:601-5.

8. Schmulewitz L, Proudfoot A, Bell D. The impact of weekends on outcome for emergency patients. Clin Med 2005;5:621-5.

9. Shaheen AA, Kaplan GG, Myers RP. Weekend versus weekday admission and mortality from gastrointestinal hemorrhage due to peptic ulcer disease. Clin Gastroenterol Hepatol 2009;7:303-10.

10. Garcia-Tsao G, Sanyal AJ, Grace ND, Carey W. Prevention and management of gastroesophageal varices and variceal hemorrhage in cirrhosis. Hepatology 2007;46:922-38.
11. de Franchis R. Evolving consensus in portal hypertension. Report of the Baveno IV consensus workshop on methodology of diagnosis and therapy in portal hypertension. J Hepatol 2005;43:167-76.

12. HCUP Databases. Healthcare Cost and Utilization Project (HCUP). 1998-2005. Agency for Healthcare Research and Quality, Rockville, Maryland. <www.hcup-us.ahrq.gov/databases.jsp> (Version current at February 10, 2009).

13. Whalen D, Houchens R, Elixhauser A, 2004 HCUP Nationwide Inpatient Sample (NIS) Comparison Report. HCUP Method Series Report \# 2007-03. U.S. Agency for Healthcare Research and Quality. <http://www.hcup-us.ahrq.gov/reports/methods.jsp> (Version current at February 10, 2009).

14. Myers RP, Papay KD, Shaheen AA, Kaplan GG. Relationship between hospital volume and outcomes of esophageal variceal bleeding in the United States. Clin Gastroenterol Hepatol 2008;6:789-98.

15. International Classificiation of Diseases, 9th Revision, Clinical Modification (ICD-9-CM). Practice Management Information Corporation, 2001.

16. U.S. Department of Labor: Bureau of Labor Statistics. Consumer Price Index - All Urban Consumers (U.S. Medical Care 1982-1984=100). $<$ http://www.bls.gov/cpi/home.htm> (Version current at February 10, 2009).

17. Elixhauser A, Steiner C, Harris DR, Coffey RM. Comorbidity measures for use with administrative data. Med Care 1998;36:8-27.

18. Myers RP, Quan H, Hubbard JN, Shaheen AA, Kaplan GG. Predicting in-hospital mortality in patients with cirrhosis: Results differ across risk adjustment methods. Hepatology 2009;49:568-77.

19. D’Amico G, De Franchis R. Upper digestive bleeding in cirrhosis. Post-therapeutic outcome and prognostic indicators. Hepatology 2003;38:599-612.

20. Chalasani N, Kahi C, Francois F, et al. Improved patient survival after acute variceal bleeding: A multicenter, cohort study. Am J Gastroenterol 2003;98:653-9.

21. Carbonell N, Pauwels A, Serfaty L, Fourdan O, Levy VG, Poupon R. Improved survival after variceal bleeding in patients with cirrhosis over the past two decades. Hepatology 2004;40:652-9.

22. El-Serag HB, Everhart JE. Improved survival after variceal hemorrhage over an 11-year period in the Department of Veterans Affairs. Am J Gastroenterol 2000;95:3566-73.

23. Thomopoulos K, Theocharis G, Mimidis K, et al. Improved survival of patients presenting with acute variceal bleeding. Prognostic indicators of short- and long-term mortality. Dig Liver Dis 2006;38: 899-904.

24. Chalasani N, Kahi C, Francois F, et al. Model for end-stage liver disease (MELD) for predicting mortality in patients with acute variceal bleeding. Hepatology 2002;35:1282-4.

25. Dy SM, Cromwell DM, Thuluvath PJ, Bass EB. Hospital experience and outcomes for esophageal variceal bleeding. Int J Qual Health Care 2003;15:139-46.

26. Liang KY, Zeger SL. Longitudinal data analysis using generalized linear models. Biometrika 1986;73:13-22.

27. Houchens R, Elixhauser A. Final report on calculating Nationwide Inpatient Sample (NIS) variances, 2001. HCUP Methods Series Report \#2003-2. U.S. Agency for Healthcare Research and Quality. $<$ http://www.hcup-us.ahrq.gov/reports/2003_2.jsp> (Version current at February 10, 2009).

28. Bell CM, Redelmeier DA. Waiting for urgent procedures on the weekend among emergently hospitalized patients. Am J Med 2004;117:175-81.

29. Hill DB, Stokes BD, Gilinsky NH. Arterial oxygen saturation during emergency esophagogastroduodenoscopy. The effects of nasal oxygen. J Clin Gastroenterol 1994;18:284-6.

30. Ellis SG, Miller DP, Brown KJ, et al. In-hospital cost of percutaneous coronary revascularization. Critical determinants and implications. Circulation 1995;92:741-7.

31. Iezzoni LI. Coded data from administrative sources. In: Iezzoni LI, ed. Risk Adjustment for Measuring Health Care Outcomes, 3rd edn. Chicago: Health Administration Press, 2003:83-138. 


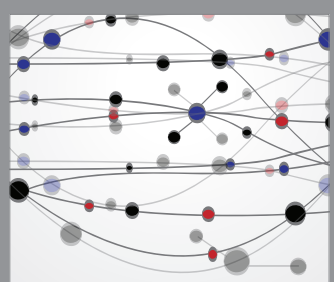

The Scientific World Journal
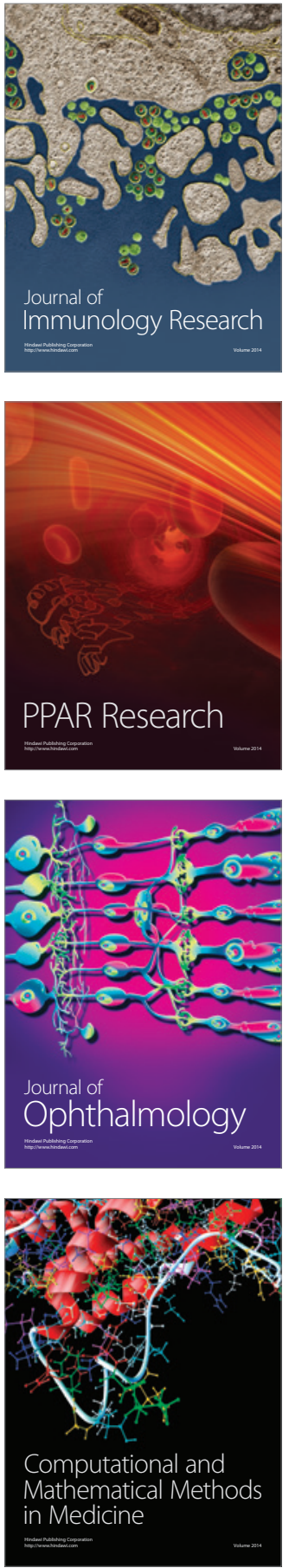

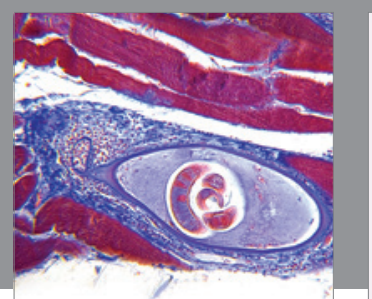

Gastroenterology Research and Practice

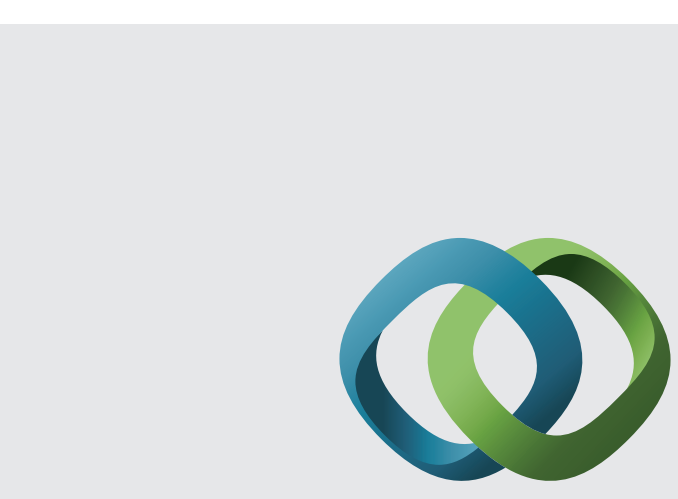

\section{Hindawi}

Submit your manuscripts at

http://www.hindawi.com
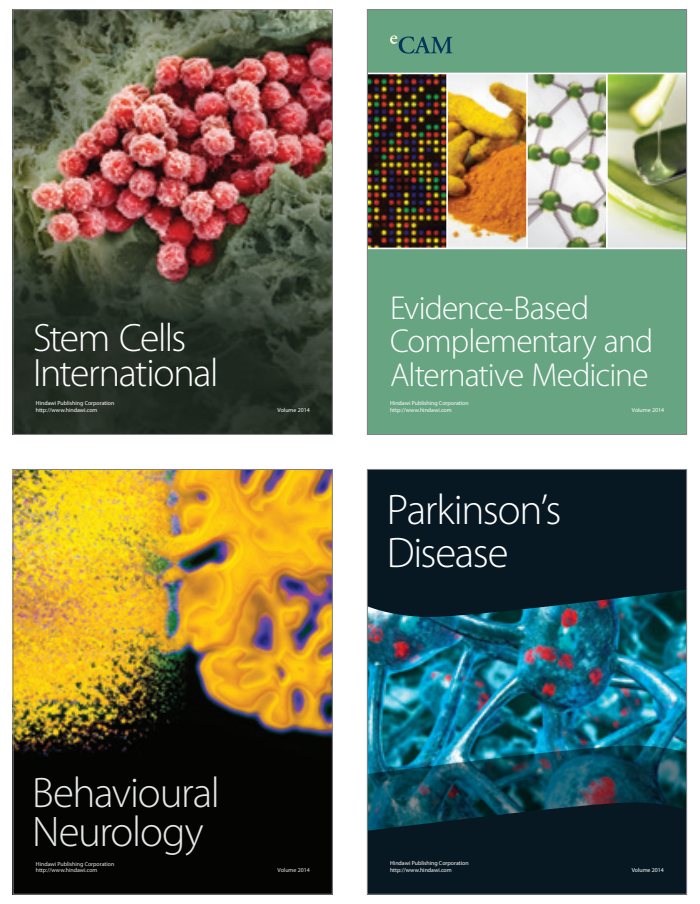
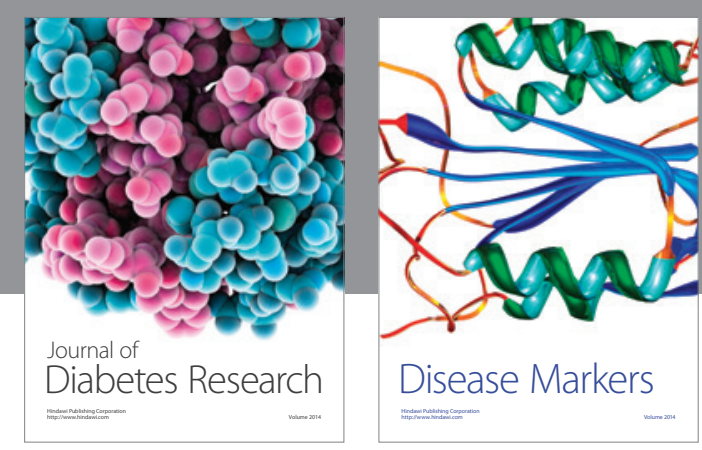

Disease Markers
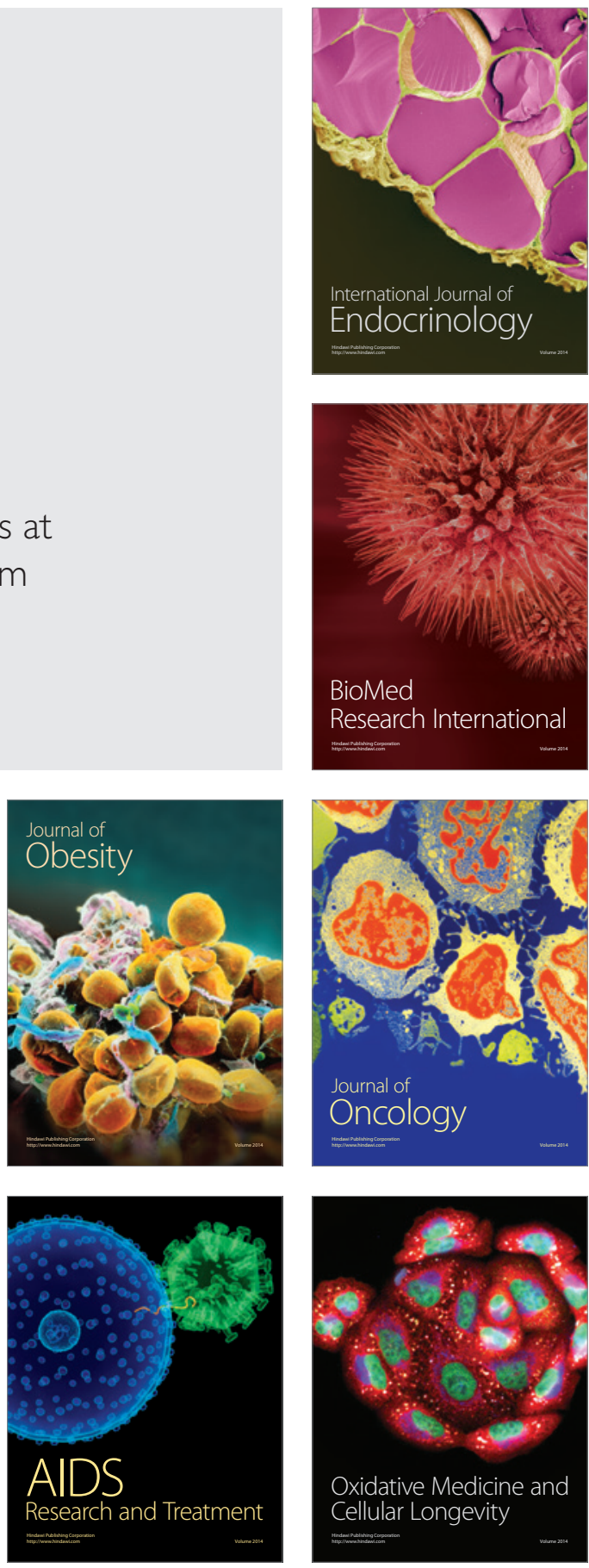